\section{Analysis on the operation mechanism of the ecosystem of crowd innovation space based on grounded theory}

Ecosystem of crowd innovation space

\author{
$\mathrm{Wu}$ Wei and Hui Ni \\ Wuhan University, Wuhan, China
}

\begin{abstract}
Purpose - The purpose of this paper is to study the operation mechanism of the ecosystem of crowd innovation space. Though the crowd innovation space is a new product of China's innovation-driven strategy, there are some barriers in operation. So, this problem is worthy of study.

Design/methodology/approach - In this study, data were obtained through four-month field investigation and semistructured interview, then classified and analyzed through grounded theory, because grounded theory is conducive to the exploration and discovery of new theories.

Findings - This study finds that the relationship between makerspace and entrepreneurs is strong social relational embeddedness. The relationship between crowd innovation space and governments and investment institutions is economic relational embeddedness. Under these social network ties, entrepreneurs, crowd innovation space, social investment institutions and so on can interact directly with each other to different degrees, carry out value cocreation activities and improve the benefits of all elements in the ecosystem and the ecosystem itself.

Originality/value - This study researches the operation mechanism of crowd innovation space ecosystem and identifies the ties between various elements in the ecosystem on the perspective of social network, which is conducive to improve the self-generating capacity of crowd innovation space and enhance the success rate of entrepreneurship.
\end{abstract}

Keywords Crowd innovation space, Economic relationship embeddedness, Social relationship embeddedness, Value cocreation

Paper type Research paper

\section{Introduction}

Since the 18th national congress of the Communist Party of China, China's economy is undergoing a transformation from tradition to innovation; in the meantime, the economic growth rate has been shifted from high speed to medium-high speed. At the critical time of China's economic transformation, crowd innovation space has turned into an indispensable of China's "mass entrepreneurship, mass innovation" strategy, bearing a vital mission of innovative development (Li et al., 2017; Lin et al., 2016). Crowd innovation space changes the traditional innovation and entrepreneurship mode from top to bottom, which makes the innovation and entrepreneurship subject diversified. Through resource integration and professional services, crowd innovation space makes innovation and entrepreneurship faster and easier, which plays a great role in China's "mass entrepreneurship and innovation" strategy (Li et al., 2016). With the strong support of governments at all levels, the development

(C) Wu Wei and Hui Ni. Published in Journal of Industry-University Collaboration. Published by Emerald Publishing Limited. This article is published under the Creative Commons Attribution (CC BY 4.0) licence. Anyone may reproduce, distribute, translate and create derivative works of this article (for both commercial and non-commercial purposes), subject to full attribution to the original publication and authors. The full terms of this licence may be seen at http://creativecommons.org/licences/by/4.0/legalcode

The work was financially supported by the National Social Science Key Fund of China (18AGL006) and the Social Science Foundation of the Ministry of Education of China (17YJA630105).
Received 19 February 2020

Revised 7 April 2020
Accepted 7 April 2020

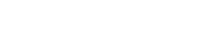


JIUC 2,2

80

of crowd innovation space presents a prosperous scene, but in fact, there are serious homogenization problem in field of crowd innovation space. In addition, most of the crowd innovation spaces are lack of resource integration ability and self-generating ability and the like (Li and Chen, 2017). Through investigation, our research team found that many crowd innovation spaces failed to grasp the pain points of entrepreneurs, failed to solve the core problems for the entrepreneurial team, leading to low incubation efficiency. It has aroused the attention of the government and the operators of crowd innovation spaces - how to establish a crowd innovation space ecosystem for the national innovation-driven strategy and make it sustainable? These are two of our research questions.

At present, there are many researches on the components of crowd innovation space ecosystem. Studies have shown that crowd innovation space ecosystem is a complex adaptive system with multiple participants, including entrepreneurs, crowd innovation space, government, universities, intermediary service institutions, financial investment institutions and so on. (Roundy et al., 2018; Li et al., 2014). Xie and Liu (2018) drew lessons from the ecosystem of "makerspace + incubator + Living Lab" and concluded that China's crowd innovation space is a comprehensive service platform integrating the functions of "innovation" and "entrepreneurship" and "investment" and "incubator" (Xie and Liu, 2018). Neck et al. (2004) revealed that the entrepreneurial ecosystem consists of two parts via a twostage research. The first part is related to the incubator; the second part is the formal and informal networks, infrastructure and community culture composed of universities, government, professional support services, capital services, intellectual resources and large enterprises. Therefore, based on the literature review, this study believes that the crowd innovation space is a center of the ecosystem with the goal of incubating innovation and entrepreneurship and connecting with the government, universities, enterprises, intermediary service organizations, social investment institutions and related environmental supporting elements in specific geographic space. There are few researches on the operation mechanism of the crowd innovation space ecosystem (Chen and Li, 2018; Autio, Nambisan and Thomas, 2018). After development over more than four years, the crowd innovation space ecosystem has not yet formed a theoretical system for the operation mechanism.

This study is based on the perspective of social network theory, combining relevant policy documents, media reports and other second-hand materials of crowd innovation space to design an interview outline (Ahuja, 2000). Our researchers obtained first-hand information through face-to-face interviews with the founders or principals of crowd innovation spaces, then, sorted out the text of the recordings and selected effective sentences centering on the connection between the crowd innovation space and other elements of the ecosystem. It is of theoretical and practical significance to explore the internal operation mechanism of crowd innovation space ecosystem by means of grounded theory and three-level coding.

\section{Research design}

\subsection{Data}

In order to improve the universality and reliability of this research, our researchers followed the following three principles: first, choose various types of crowd innovation spaces; second, select crowd innovation spaces with high influence, including the local crowd innovation space and the introduced crowd innovation space; third, the research team collected the data through face-to-face interviews, visits, media reports and internal information, so as to make the data comprehensive and fair. In the end, 13 crowd innovation spaces were selected, with their key information as follows (Table 1).

\subsection{Data analysis and coding}

The researchers conducted open coding for 13 cases by using double-blind method, which was respectively by two researchers to conceptualization of raw data, then in accordance with 


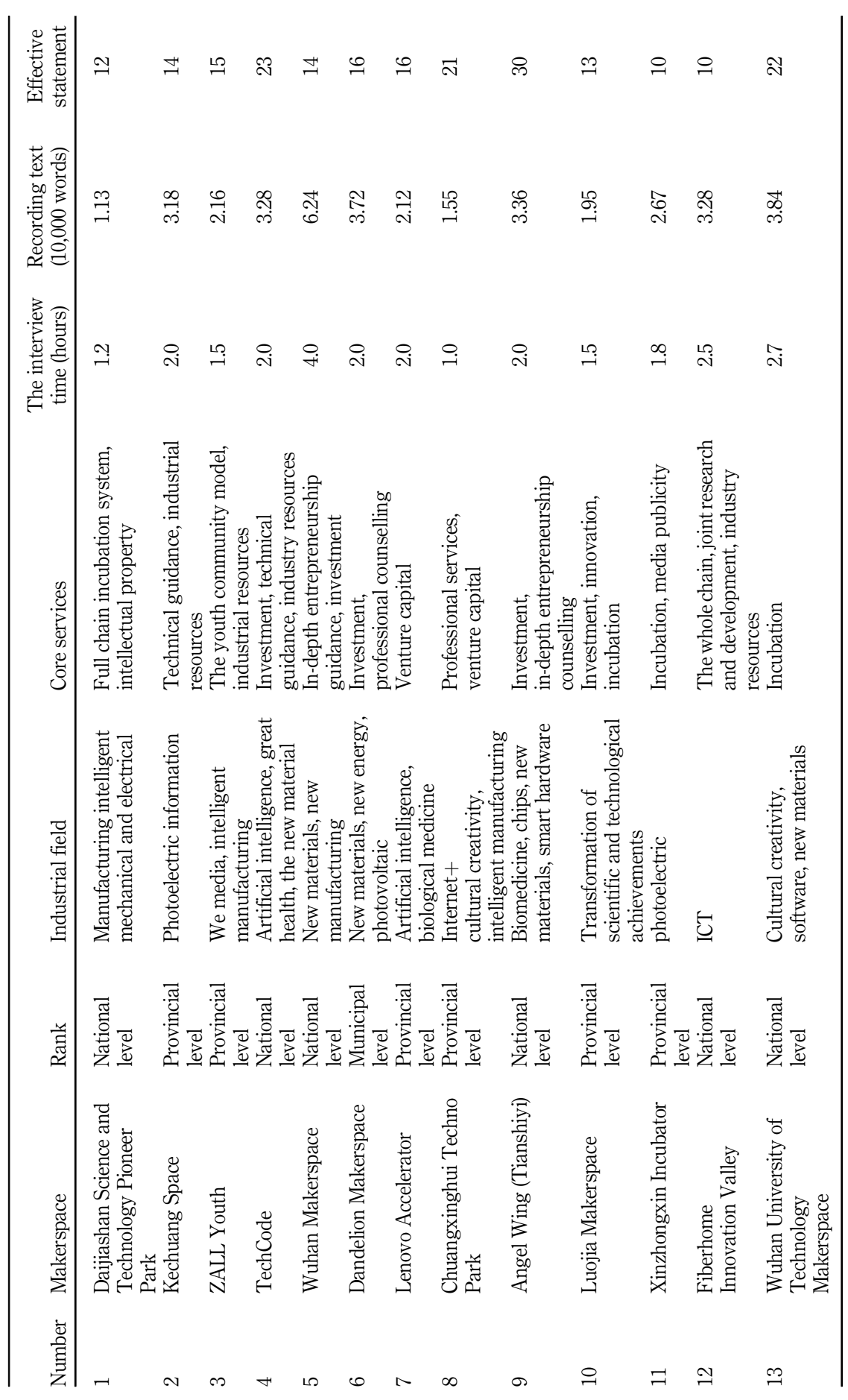

Ecosystem of crowd innovation space 81

Table 1. Summary table of 13 makerspaces 
JIUC

2,2

\section{2}

3. Case study and discovery

3.1 Open coding

Open coding marks the actions or events by analyzing, summarizing and refining the statements in the original data or quoting viewpoints based on the original data (Juliet and Anselm et al., 2015). The open coding about the operation mechanism of crowd innovation ecosystem is shown in Table 3.

\subsection{Axial coding}

On the basis of open decoding, from the perspective of social network theory, the internal relations among conceptual categories are explored (Juliet and Anselm, 2015; Spigel and Harrison, 2018). The axial coding of the ecosystem operation mechanism of crowd innovation space is shown in Table 4.

(1) Social relationship embeddedness refers to the intangible affective ties that accumulate in the process of a series of cooperative activities (Li and Yang, 2017). From the original statement in Table 3 and the analysis in Table 4, it can be found that the integration, the fusion and mutual trust between the crowd innovation spaces and the entrepreneurs are important manifestations of social relationship embeddedness (Spigel, 2017). Through frequent and comprehensive interaction, the two sides

\begin{tabular}{|c|c|c|c|c|}
\hline \multirow[b]{2}{*}{ Makerspace } & \multirow[b]{2}{*}{$\begin{array}{c}\text { Face-to-face } \\
\text { interview } \\
\text { materials }\end{array}$} & \multicolumn{2}{|c|}{ Data sources } & \multirow[b]{2}{*}{$\begin{array}{l}\text { Internal } \\
\text { brochures } \\
\text { PPT, etc. }\end{array}$} \\
\hline & & $\begin{array}{l}\text { Site visit } \\
\text { information }\end{array}$ & $\begin{array}{l}\text { The network } \\
\text { information }\end{array}$ & \\
\hline $\begin{array}{l}\text { Daijiashan Science and } \\
\text { Technology Pioneer Park }\end{array}$ & $\mathrm{A} 1$ & B1 & $\mathrm{C} 1$ & D1 \\
\hline Kechuang Space & A2 & B2 & $\mathrm{C} 2$ & D2 \\
\hline ZALL Youth & A3 & B3 & $\mathrm{C} 3$ & D3 \\
\hline TechCode & A4 & B4 & $\mathrm{C} 4$ & D4 \\
\hline Wuhan Makerspace & A5 & B5 & $\mathrm{C} 5$ & D5 \\
\hline Dandelion Makerspace & A6 & B6 & C6 & D6 \\
\hline Lenovo Accelerator & A7 & B7 & $\mathrm{C} 7$ & D7 \\
\hline $\begin{array}{l}\text { Chuangxinghui Techno } \\
\text { Park }\end{array}$ & A8 & B8 & $\mathrm{C} 8$ & D8 \\
\hline Angel Wing (Tianshiyi) & A9 & B9 & C9 & D9 \\
\hline Luojia Makerspace & A10 & $\mathrm{B} 10$ & $\mathrm{C} 10$ & D10 \\
\hline Xinzhongxin Incubator & A11 & B11 & $\mathrm{C} 11$ & D11 \\
\hline $\begin{array}{l}\text { Fiberhome Innovation } \\
\text { Valley }\end{array}$ & $\mathrm{A} 12$ & $\mathrm{~B} 12$ & $\mathrm{C} 12$ & D12 \\
\hline $\begin{array}{l}\text { Wuhan University of } \\
\text { Technology Makerspace }\end{array}$ & A13 & B13 & $\mathrm{C} 13$ & D13 \\
\hline
\end{tabular}

Table 2.

Data encoding of 13 interviewees
Note(s): The number represents the serial number of the case, and the letter represents the data category. For example, "A1" represents the face-to-face interview data from Daijiashan Science and Technology Pioneer Park, and "B2" represents the on-site observation data from Kechuang space 


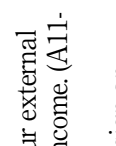

范泀.

50 0.50

อ.

롱 흔

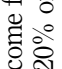

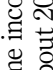

हี ซ

点

芴

글

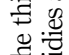

\&:

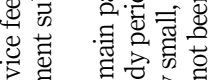

究

声宫

.20

艺密

苛

造

छ

获宫

E्ञ

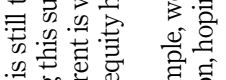

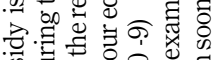

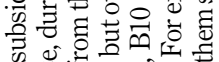

क 80.0

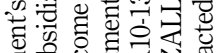

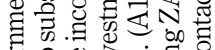

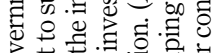

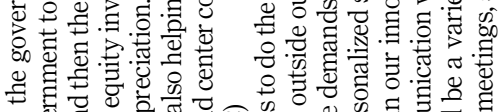

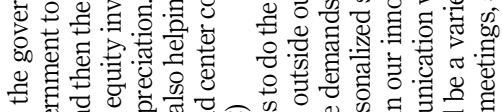

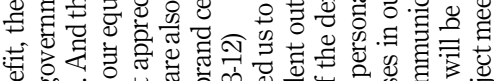

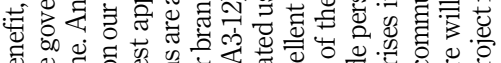

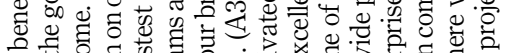

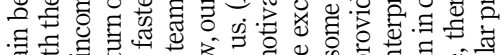

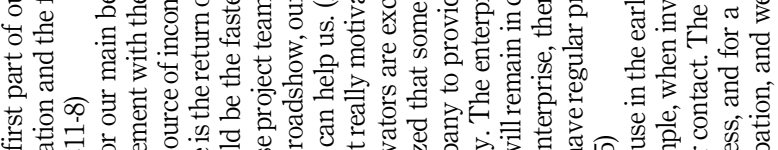

总菏

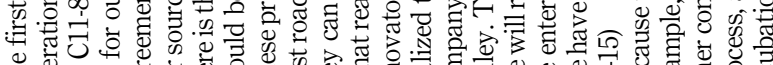

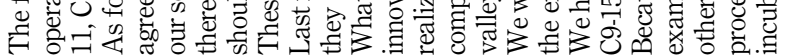

Ecosystem of

crowd innovation

space

83

Table 3

Open coding of

makerspace ecosystem

operation mechanism 
$\underset{2,2}{\text { JIUC }}$

84

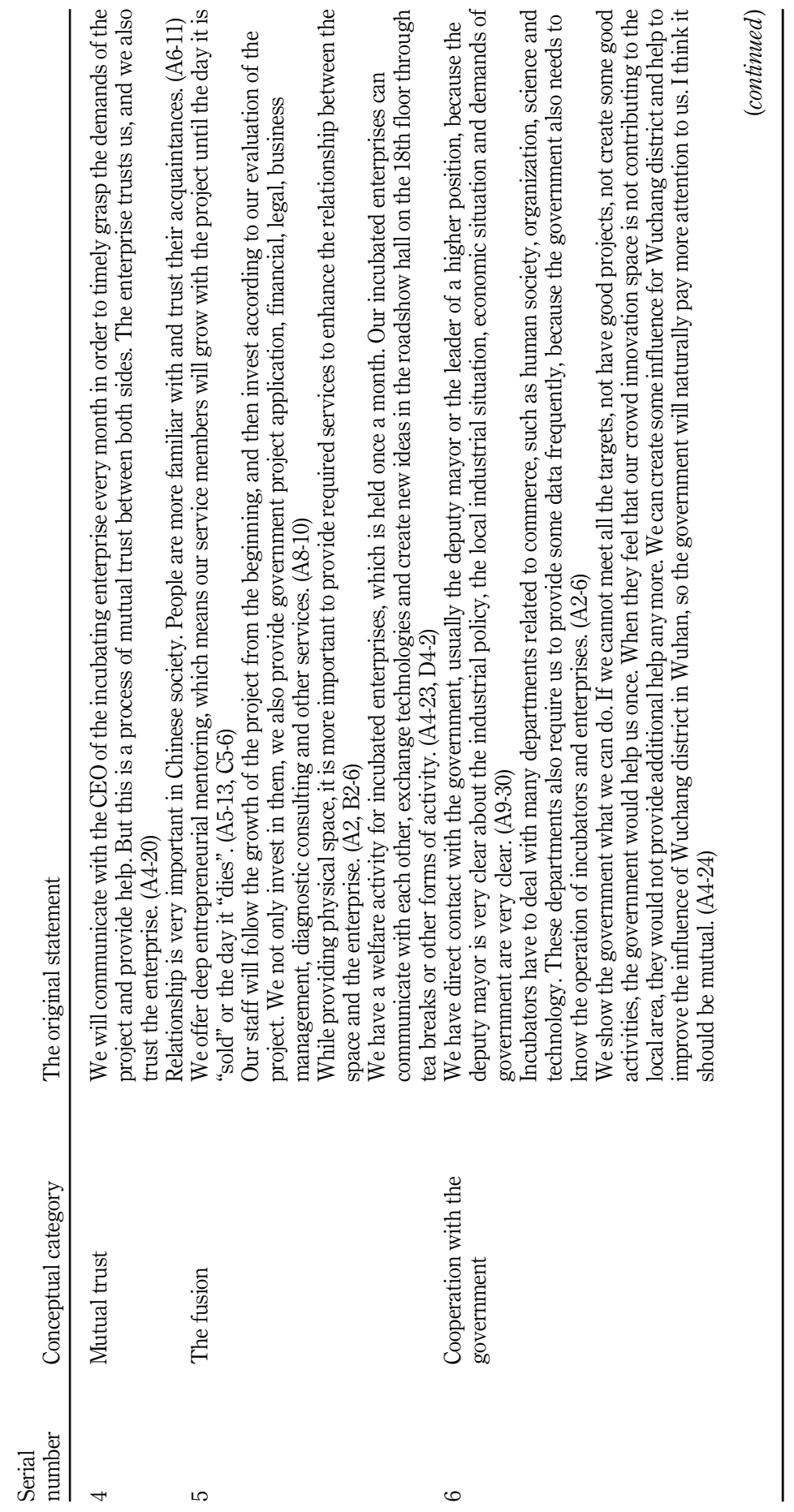




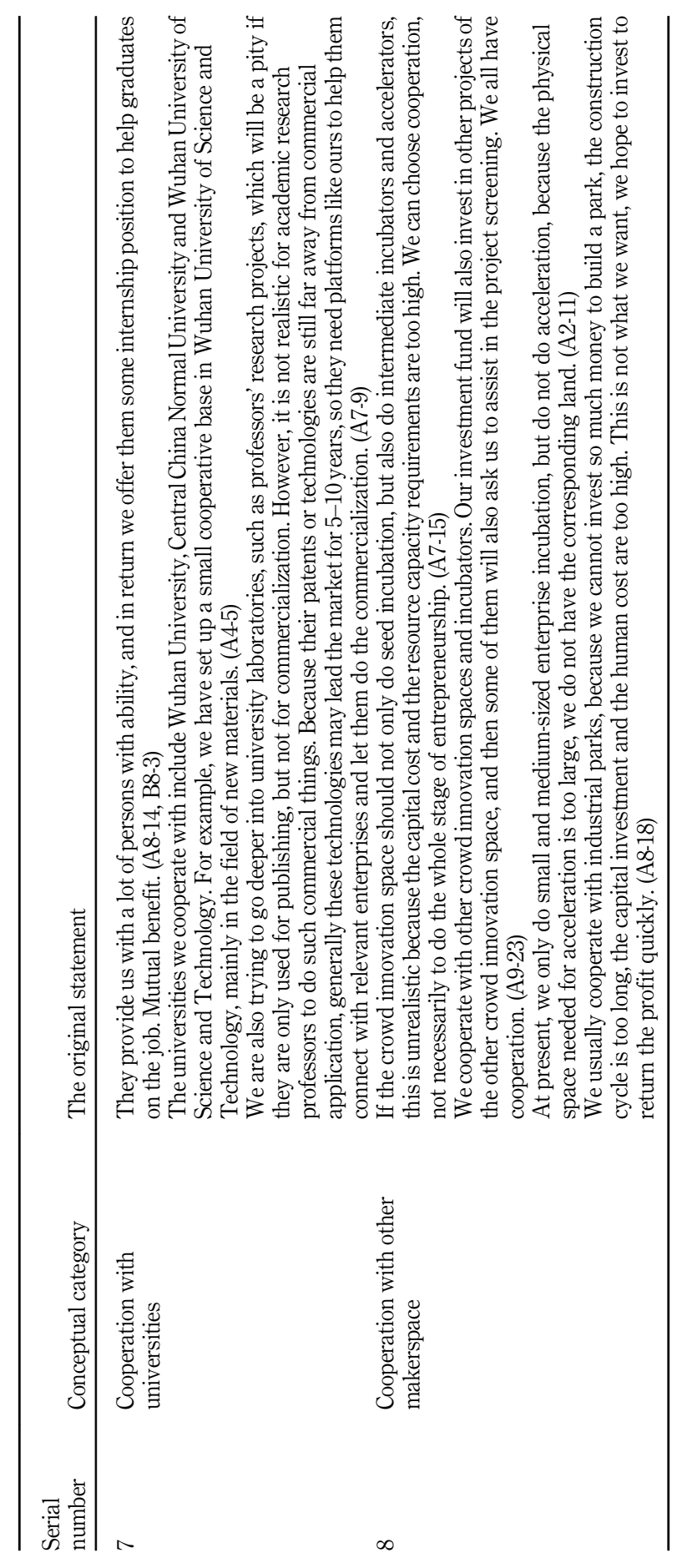

Ecosystem of crowd innovation space

85

Table 3. 
JIUC
2,2

86
Table 4.

Axial coding of ecosystem operation mechanism of crowd innovation space

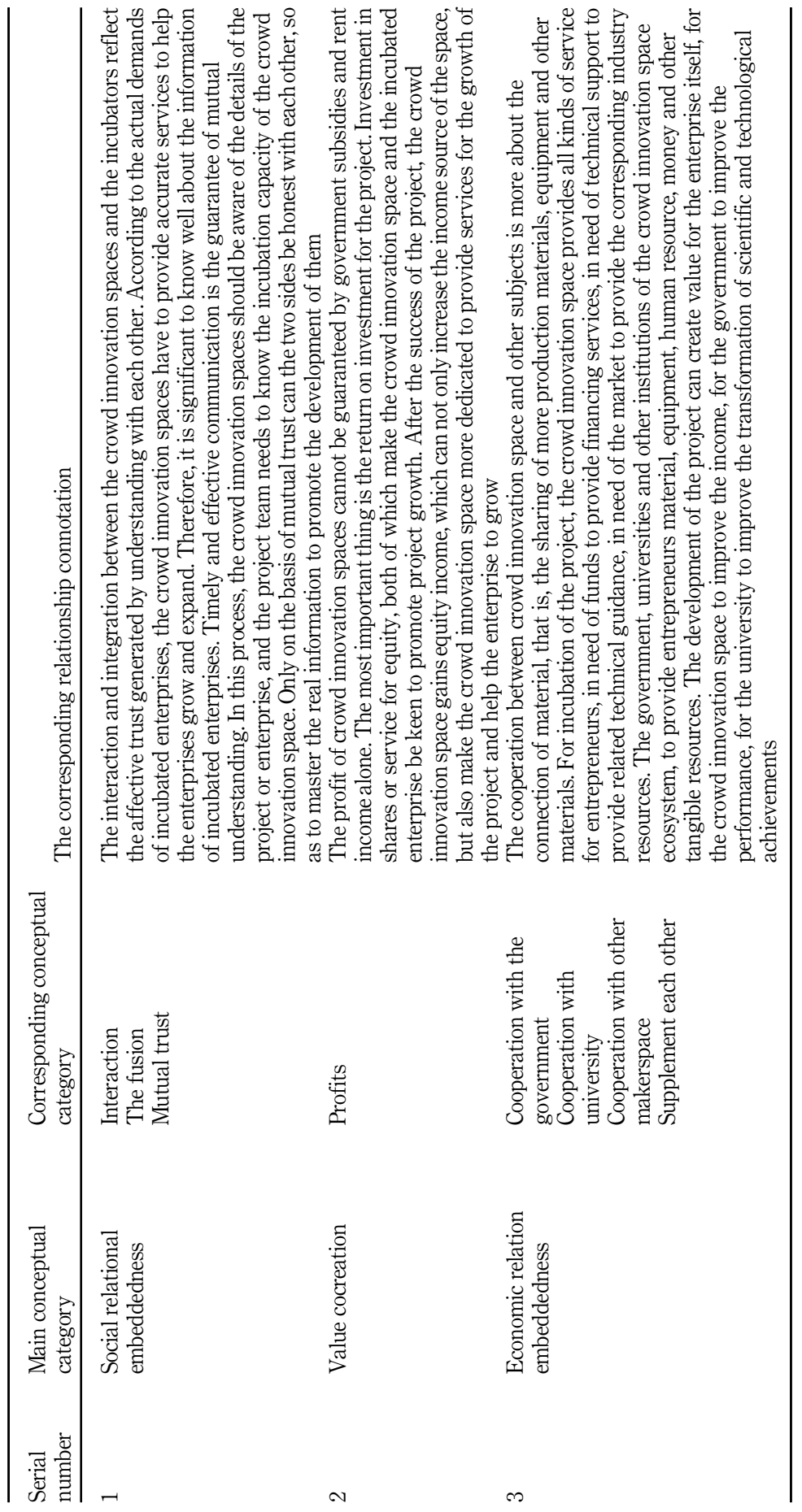


establish trust and understanding, so that the crowd innovation spaces can truly understand the development demands of the incubated enterprises, providing them with targeted services and solving the entrepreneurial problems of the incubated enterprises. This is the premise and basis for the makerspace to accurately provide services for the incubated enterprises.

(2) Economic relationship embeddedness refers to the formal interest ties between the two parties due to the input of tangible capital such as material and human resources (Li and Yang, 2017). The cooperation among the crowd innovation spaces and the government, universities is more of a connection of interests. The crowd innovation space aims to obtain the entrepreneurial resources needed by enterprises, while the government, universities and other crowd innovation spaces can also get the benefits they demand. Through cooperation with various subjects, crowd innovation space provides tangible entrepreneurial resources, such as capital, technology and talents, for incubated enterprises to help them grow.

(3) Value cocreation theory holds that value is created by customers, enterprises and a large number of stakeholders; in addition, direct interaction is the core of value cocreation. Direct interaction is a simultaneous, interwoven and conversational process (Grönroos and Voima, 2013; Aarikka-Stenroos and Jaakkola, 2012). According to Table 3, it can be found that various elements of the crowd innovation space ecosystem form an entrepreneurial ecosystem of value creation by innovation and entrepreneurship subjects, crowd innovation space, government, universities and other relevant institutions interacting with each other in order to help the start-ups grow (Roundy et al., 2018).

\subsection{Selective coding}

After the analysis of the open coding and axial coding of crowd innovation space operation mechanism, selective coding is carried out to abstract the connections between categories. The selective coding is shown in Figure 1.

\section{Model implications}

In order to make the crowd innovation space ecosystem run effectively (effective), it is needed to form a relationship embeddedness with all elements of the crowd innovation space ecosystem. The tie between crowd innovation space and entrepreneur is embedded with more attributes of social relationship, while the tie with government, universities and other elements is embedded with more attributes of economic relationship. Li et al. (2017) proposed the duality of relationship embeddedness, which is divided into economic embeddedness and social embeddedness according to its nature. Among them, economic relationship embeddedness refers to the formal interest connection between the two parties due to the input of tangible capital such as material and human resources. Social relationship embeddedness refers to the intangible affective connection formed by the two parties in the process of carrying out a series of cooperative activities centering on the relationship embeddedness. The degree of interaction between enterprises in repeated transactions determines the strength of social relationship embeddedness [11].

The social relationship between the crowd innovation space and entrepreneur is the start. In the interview, when describing the connection with incubated enterprises, the leaders of crowd innovation space emphasized the interaction, the fusion and mutual trust between the two sides. The crowd innovation space selects high-quality projects in familiar fields and interacts frequently and comprehensively with the project's founding team to get detailed
Ecosystem of crowd innovation space 

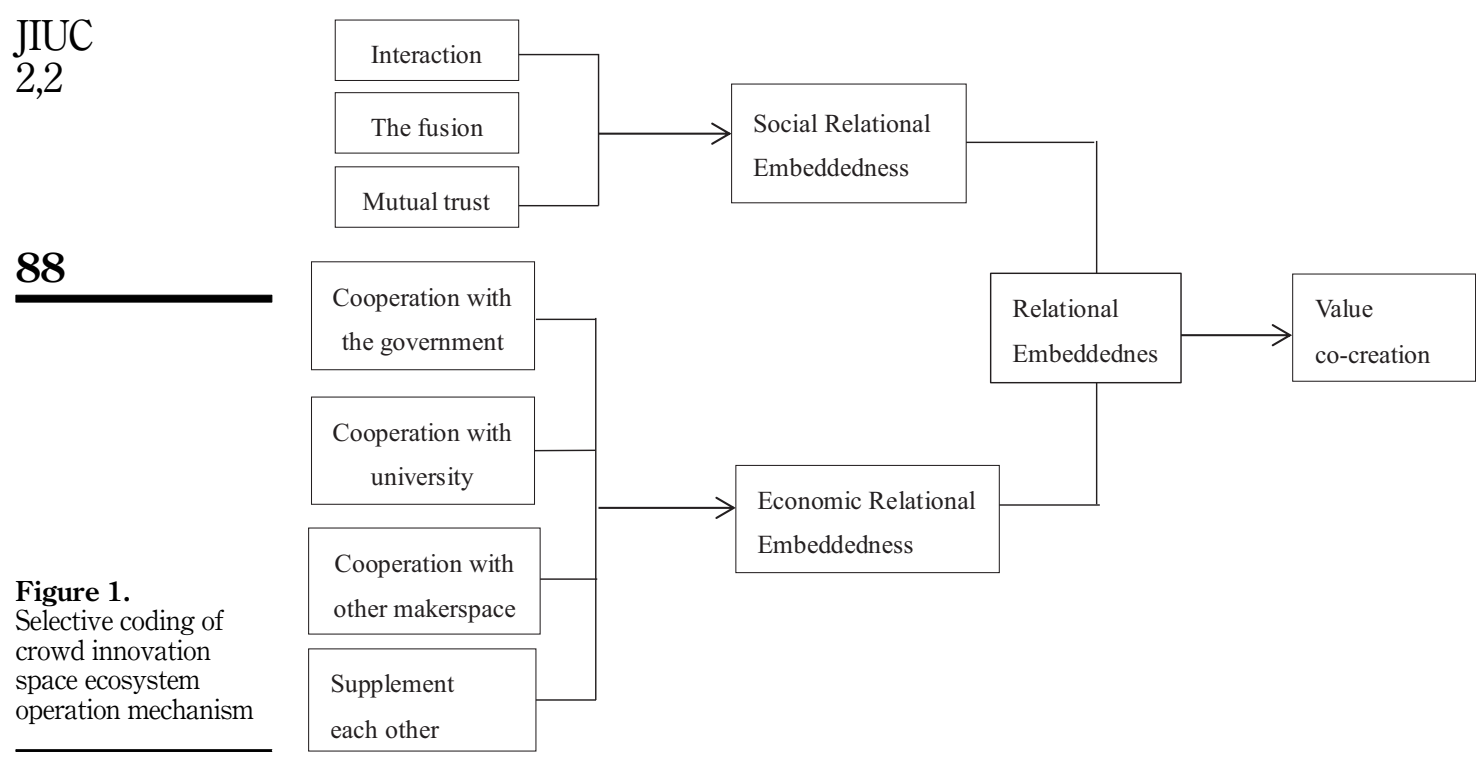

Figure 1.

Selective coding of crowd innovation space ecosystem operation mechanism

information about founders, technical field, product market, financing demand and many other aspects. The project team also got to know the basic information and service ability of the crowd innovation space and other important aspects in the interaction process. On the basis of mutual trust, the two sides communicated frankly and effectively to form in-depth interaction. Depth of interaction is not only in the beginning period, but also throughout the growth of the project until the crowd innovation space exits the equity investment of incubated enterprises. During each period of project, both sides should maintain in-depth interaction, so as to facilitate the crowd innovation space to provide accurate and practical services for the project and promote the project. In a series of cooperative activities, a strong affective tie is formed between the crowd innovation space and the entrepreneurs (Vargo et al., 2008).

The tie between the crowd innovation space and the government, universities, social investment institutions and other elements of interest generated by the input of tangible resources such as material, human and capital is equally important. The economic behaviors of both sides are affected by the network relationship between each other to varying degrees, forming the economic relationship embeddedness (He and Zhang, 2017).

In the face-to-face interview, the leader of crowd innovation space mainly mentioned the interaction and connection with the government, universities and investment institutions, but rarely mentioned the in-depth interaction with the third-party service institutions. The ability of a crowd innovation space is limited, which leads it difficult to maintain frequent interaction with every network node of the ecosystem, therefore, for some social network relationships that cannot make the crowd innovation space form unique competitiveness, they can spend less time and energy to acquire and maintain, for example, the crowd innovation space with third-party service institutions often need only through the contract in the form of the connections in a business, without the need for frequent interaction. Both sides of the economic behavior are affected by weak relationships embeddedness (Soda et al., 2018).

The crowd innovation space is embedded in the relationship with all elements of the ecosystem and has frequent interactive behaviors with some them, which provides a 
foundation for value cocreation (Alves, 2013; Christian and Annika, 2011). The core point of value co-creation is "direct interaction," without direct interaction, there is no value cocreation (Kaushik et al., 2015).

The innovators and entrepreneurs are the value source of the crowd innovation space ecosystem (Spilling, 1996; Spigel, 2017). The value of crowd innovation space is generated through direct interaction with the innovators and entrepreneurs. Through direct interaction with other elements of the ecosystem, crowd innovation space can obtain entrepreneurial resources needed for the growth of entrepreneurial enterprises and integrate government, universities and other resources to provide incubation services for projects. The value increment of a start-up comes from the process of value creation involving multiple parties (Wang and Liu, 2017).

Therefore, the value generating mechanism of the crowd innovation space ecosystem can be described as: the entrepreneurs and innovators and crowd innovation space form social relationship embeddedness, and the government, universities and other institutions form economic relationship embeddedness, in the coupling relationship between embedded in the direct interaction, then, value appreciation is generated, so as to realize the value of the crowd innovation space ecosystem.

\section{Discussion}

\subsection{The management suggestion for the crowd innovation spaces}

5.1.1 Identifying key resources. In the context of Chinese society, strong relationships are easier to obtain resources, strengthen cooperation, share knowledge and so on (Bian, 2000). Therefore, the establishment of strong relationships with key elements in the ecosystem plays an important role in the information acquisition and resource integration of crowd innovation space, which can improve their service capability. For example, the ties with third-party service institutions are necessary but not important for the crowd innovation space, because the connection between the crowd innovation space and third-party service institutions is easy to establish and maintain. As the crowd innovation space positioned at the transformation of scientific and technological achievements, then universities and research institutions with strong scientific research strength are its key resources. They should mainly focus on acquiring resources of universities and research institutes, forming strong relationship embeddedness and set acquiring other resources as their second target.

5.1.2 Social relationship embeddedness. Innovators and entrepreneurs are the most important elements in the ecosystem, because they are the source of the wealth for crowd innovation space (Mcmullen, 2018). Therefore, the crowd innovation space should mainly focus on obtaining high-quality project and entrepreneurial team, establishing strong social relationship embeddedness that can lead to trust based on mutual understanding. Then, the crowd innovation space and entrepreneurs will have a comprehensive understanding of each other and form an invisible affective tie during the process of the interaction and fusion. Crowd innovation space should have a deep understanding of the technology, market and talent demand of incubated enterprises, provide them with accurate services and practically solve the difficulties in the process of entrepreneurship. The mission of crowd innovation spaces is to help entrepreneurial enterprises to obtain entrepreneurial resources contributing to development and growth. Therefore, it is more important to establish social relationship embeddedness between the crowd innovation space and incubated enterprises so as to promote the common benefits of crowd innovation space ecosystem.

5.1.3 Economic relationship embeddedness. Social investment institutions, financial service institutions, large enterprises providing industrial resources and other elements in the crowd innovation space ecosystem are all profit-making organizations. With the goal
Ecosystem of crowd innovation space 
JIUC
2,2

of pooling entrepreneurial resources, crowd innovation space cooperates with such organizations in terms of tangible capital to form formal interest ties. Economic relationship embeddedness is mostly aimed at economic benefit, based on the material interaction between enterprises, centering on the investment of assets and equipment. As an incubation service organization, crowd innovation space should form an economic relationship embeddedness with these entrepreneurial resources to integrate them for incubated enterprises so as to improve the entrepreneurial service capabilities of themselves.

\subsection{Future research direction}

5.2.1 Research from the perspective of structural embeddedness. Granovetter (1985) divided embeddedness network into relationship embeddedness and structural embeddedness, two dimensions (Granovetter, 1985). This study focuses on the relationship embeddedness analysis; while it can be analyzed on the perspective of structural embeddedness in future, dig out the structure of the crowd innovation space ecosystem network through network location, network density and network scale and improve the understanding of the social network of crowd innovation space ecosystem.

5.2.2 Transition from qualitative research to quantitative research. The research data on the crowd innovation space ecosystem can be transformed from semistructured interview to questionnaire collection and from qualitative analysis to quantitative analysis. Questions related to the communication between crowd innovation space and other elements in the ecosystem can be transformed into questionnaires. The combination of qualitative analysis and quantitative analysis makes the results more accurate and reliable.

5.2.3 Research from different subject perspectives. The elements of crowd innovation space ecosystem are multitudinous, including entrepreneurs, crowd innovation space and the government and so on. In a different perspective to explore the social network and the value creation mechanism of crowd innovation space ecosystem can help us to understand the inner mechanism of crowd innovation space ecosystem more comprehensively.

\section{References}

Aarikka-Stenroos, L. and Jaakkola, E. (2012), "Value co-creation in knowledge intensive business services: a dyadic perspective on the joint problem-solving process", Industrial Marketing Management, Vol. 41 No. 1, pp. 15-26.

Ahuja, G. (2000), "Collaboration networks, structural holes, and innovation: a longitudinal study", Administrative Science Quarterly, Vol. 45 No. 3, pp. 425-455.

Alves, H. (2013), "Co-creation and innovation in public services", Service Industries Journal, Vol. 33 No. 7 , pp. 671-682.

Autio, E., Nambisan, S. and Thomas, L.D.W. (2018), "Digital affordances, spatial affordances, and the genesis of entrepreneurial ecosystems", Strategic Entrepreneurship Journal, Vol. 12 No. 1, pp. 72-95.

Bian, Y.J. (2000), "The social capital of enterprises and its efficiency", Social Sciences in China No. 2, pp. 87-99.

Chen, W. and Li, Y.P. (2018), "The competitiveness cultivation of platform organization under the perspective of embeddedness: a multiple-case study of maker spaces”, Economic Management No. 3, pp. 74-92.

Christian, G. and Annika, R. (2011), "Service as business logic: implications for value creation and marketing", Journal of Service Management, Vol. 22 No. 1, pp. 5-22. 
Granovetter, M. (1985), "Economic action and social structure: the problem of embeddedness", American Journal of Sociology, Vol. 91 No. 3, pp. 481-510.

Grönroos, C. and Voima, P. (2013), "Critical service logic: making sense of value creation and cocreation", Journal of the Academy of Marketing Science, Vol. 41 No. 2, pp. 133-150.

He, Y.B. and Zhang, Y.C. (2017), "A study on the impact of network embeddedness on industryuniversity-research institute knowledge collaboration performance", Studies in Science of Science, No. 9, pp. 118-130.

Juliet, M.C. and Anselm, L.S. (2015), The Foundation of Qualitative Research: Procedures and Methods for Forming the Grounded Theory, Chongqing university press, Chongqing.

Kaushik, A.K., Agrawal, A.K. and Rahman, Z. (2015), "Co-creation of social value through integration of stakeholders", International Conference of the Society of Operations Management, Vol. 189 No. 25, pp. 442-448.

Li, Y.P. and Chen, W. (2017), "The research actuality and future prospect of crowd innovation space", Forum on Science and Technology in China No. 5, pp. 12-18.

Li, D. and Yang, J.J. (2017), "The moderating paths of dual relationship embeddedness on relationship between opportunistic behavior and equity governance", Nankai Business Review No. 4, pp. 129-139.

Li, W., Chang, J. and Wang, M.J. (2014), "Innovation 3.0 and innovation ecosystem", Studies in Science of Science, Vol. 32 No. 12, pp. 1761-1770.

Li, Y.P., Chen, W. and Li, Z.H. (2016), "The strategy to drive China's innovation by developing maker and crowd innovation space: theories and practices", Science and Technology Progress and Policy, Vol. 33 No. 20, pp. 154-160.

Li, Y.P., Chen, W. and Chen, J.A. (2017), "Research on the ecological network elements and capacity generation of maker-oriented platform organization", Economic Management No. 6, pp. 103-117.

Lin, X., Gao, S. and Liu, X.L. (2016), "Makerspace's basic types,commercial models and theoretical value”, Studies in Science of Science, Vol. 34 No. 6, pp. 923-929.

Mcmullen, J.S. (2018), "Organizational hybrids as biological hybrids: insights for research on the relationship between social enterprise and the entrepreneurial ecosystem", Journal of Business Venturing, Vol. 33 No. 6, pp. 575-590.

Neck, H.M., Meyer, G.D. and Cohen, B. (2004), "An entrepreneurial system view of new venture creation”, Journal of Small Business Management, Vol. 42 No. 2, pp. 190-208.

Roundy, P.T., Bradshaw, M. and Brockman, B.K. (2018), "The emergence of entrepreneurial ecosystems: a complex adaptive systems approach", Journal of Business Research, Vol. 86, pp. 1-10.

Soda, G., Tortoriello, M. and Iorio, A. (2018), "Harvesting value from brokerang: individual strategic orientation structural holes and performance", Academy of Management Journal, Vol. 61 No. 3, pp. 896-918.

Spigel, B. (2017), "The relational organization of entrepreneurial ecosystems", Entrepreneurship: Theory and Practice, No. 1, pp. 45-72.

Spigel, B. and Harrison, R. (2018), “Towards a process theory of entrepreneurial ecosystems”, Strategic Entrepreneurship Journal, No. 12, pp. 151-168.

Spilling, O.R. (1996), "The entrepreneurial system: on entrepreneurship in the context of a megaevent”, Journal of Business Research, Vol. 36 No. 1, pp. 91-103.

Vargo, S.L., Maglio, P.P. and Akaka, M.A. (2008), "On value and value co-creation: a service systems and service logic perspective", European Management Journal, Vol. 26 No. 3, pp. 145-52.

Wang, L.P. and Liu, X.L. (2017), "Characteristics and operation mechanism of the four crowds integration in the maker space from the create value perspective", Forum on Science and Technology in China, No. 3, pp. 109-116.
Ecosystem of crowd innovation space 
JIUC

2,2

92
Xie, X.F. and Liu, Q.L. (2018), "Ecological model of mass-innovation space in the era of innovation2.0: comparison and enlightenment at home and abroad", Studies in Science of Science, Vol. 36 No. 4, pp. 577-585.

\section{Corresponding author}

Hui Ni can be contacted at: nihuimail@163.com

For instructions on how to order reprints of this article, please visit our website: www.emeraldgrouppublishing.com/licensing/reprints.htm Or contact us for further details: permissions@emeraldinsight.com 